\title{
Expanding Technological Capabilities of The Combined Hardening of Steel by Deformation
}

\author{
Andrei Kirichek ${ }^{1,}{ }^{*}$, Oleg Fedonin ${ }^{1}$, Dmitry Solovyov ${ }^{2}$ and Svetlana Fedonina ${ }^{1}$ \\ ${ }^{1}$ Bryansk State Technical University, 7, 50 let Octyabrya Blvd, Bryansk, 241035, the Russian \\ Federation \\ ${ }^{2}$ Murom Institute of Vladimir State University, 23, Orlovskaya street, 602264, Myrom, the Russian \\ Federation
}

\begin{abstract}
The technology of wave deformation hardening of metal machine parts is described, which allows obtaining a hardened surface layer up to $10 \mathrm{~mm}$ deep. The article presents the results of studying the microstructure and hardness of the samples strengthened as a result of chemical heat treatment and combined hardening consisting of preliminary wave deformation hardening and subsequent chemical heat treatment of structural alloyed steel $15 \mathrm{CrC} 2 \mathrm{Ni} 2 \mathrm{Mg}$. It is established that a preliminary impact on the cemented material by a deformation wave contributes to creating uniformly high packing density of martensite, as well as smaller sizes of martensite needles in the subsurface layer and at the border of the cemented layer, in the core of the sample and contributes to the absence of large-needle martensite. Applying this technology allows forming a high uniform hardness at $65 \mathrm{HRC}$ at a depth of $1.5 \mathrm{~mm}$, with its gradual reduction to the core of the sample, while maintaining a high level of toughness. The results obtained allow recommending wave deformation hardening and the combined technology based on it to improve the performance properties of variable machine parts that operate under the conditions of sliding friction and impact loads.
\end{abstract}

\section{Introduction}

The real service life of machines and mechanisms is largely determined by the durability of the critical heavy-duty parts. Their performance loss is usually associated with the surface layer destruction, therefore, increasing its operational properties is an important technological task [1]. Cementation is a well-known method of chemical heat treatment, providing, due to carbon saturation, a significant increase in the surface layer hardness of machine parts, reaching 58-64 HRC, while maintaining high viscosity of their core $[2,3]$.

Traditionally, to ensure the required surface microgeometry, after cementation, final machining is used, the allowance for which often reaches $0.5 \mathrm{~mm}$. Therefore, to ensure the required thickness of the treated part cemented layer, it is necessary to carry out cementation to a greater depth.

Raising the cemented layer thickness at an average cementation rate of $0.1 \mathrm{~mm} / \mathrm{h}$ makes it necessary to prolong the cementation by 3-5 hours and it causes cost increase, primarily energy costs.

\footnotetext{
* Corresponding author: fedonina.sv2015@gmail.com
} 
To improve the cementation performance, the technology of combined hardening by surface plastic deformation (SPD) with subsequent cementation is quite promising. Applying SPD before the cementation, increasing the dislocation density, intensifies diffusion processes and allows achieving higher values of carbon concentration in the diffusion zone. It is possible to reduce the time and energy costs associated with the carburizing process. The surface layer, hardened by the combined treatment of SPD and the cementation, has additional resources to improve the performance characteristics of the part.

Based on analysing studies of combined hardening of SPD and the cementation, it is found that the greatest effect is achieved by combining the operations that provide approximately equal thickness of the hardened SPD and the diffusion obtained during cementing the layers. The widely used methods of SPD such as run-in, smoothing, shotblasting do not always allow creating a hardened layer with a depth which is not less than under cementing.

The technology of wave deformation hardening (WDH) of machine metal parts is carried out, for which a pulse generator is used, the main elements of which are the head and the waveguide [4]. When hardening, the striker hits the waveguide, which is statically pressed against the hardened surface. As a result, plane acoustic waves are generated in the strike-waveguide shock system, which are characterized by the law of force variation (strain amplitude) over time, maximum force, force action time (strain wave duration), and strain energy. These characteristics depend on the geometry of the colliding striker and waveguide, the properties of their materials and the collision speed. The period of such a wave is called a shock pulse. The shape of the shock pulse entering the deformation zone, i.e. the area of the tool contact with the material to be hardened determines the effectiveness of dynamic loading. Pre-static compression of the waveguide contributes to the most complete use of the pulsed load for plastic deformation of the hardened material. The form of shock pulses maximally adapts to the material properties and loading conditions, which increases the efficiency of the process, expands the technological capabilities of processing, allowing creating a deep reinforced layer [5-8].

Wave deformation effect, depending on the properties of the source material and processing modes, allows modifying the material to a depth of $0.1-0.3 \mathrm{~mm}$ to $10 \mathrm{~mm}$., differs by controlled reinforcement of the inner metal layers by alternating areas of increased hardness and high viscosity with diffuse phase boundaries, which contributes to a multiple increase in the carrying capacity and resource of the product [9-17].

An important feature of the WDH method is the possibility of precise control of the transmitted energy to a given surface area of the hardened metal, and the dimensions of such a section can be from 1-2 $\mathrm{mm}$ to $50 \mathrm{~mm}$. This feature allows adjusting the required depth, degree and uniformity of hardening in a wide range.

\section{Research description}

The effectiveness of combined wave hardening and deformation by the cementation has been investigated for structural alloyed steels 20Cr2Ni4A and 18CrMnTi used for cemented parts of critical purpose, as well as for structural low alloyed steel $10 \mathrm{CrCNiCu}$.

The results obtained allow speaking about the effect of preliminary wave deformation hardening on the cementation process with combined hardening, and for each group of steels this effect will be different.

It is established that the preliminary effect on a cemented material by a deformation wave contributes to increasing the depth of the cemented layer and the degree of combined hardening along the layer depth; however, this increase is different for various materials. Combined hardening of steel $20 \mathrm{Cr} 2 \mathrm{Ni} 4 \mathrm{~A}$ and $10 \mathrm{CrCNiCu}$ contributes to increasing the 
hardening degree of the cemented layer, respectively, by $25 \%$ and $10 \%$. When hardening steel $10 \mathrm{CrCNiCu}$ maximum hardness reaches $62 \mathrm{HRC}$, and steel $20 \mathrm{Cr} 2 \mathrm{Ni} 4 \mathrm{~A}$ and $18 \mathrm{CrMnTi}$, respectively $60 \mathrm{HRC}$ and $58 \mathrm{HRC}$. The depth of the cemented layer of steel $10 \mathrm{CrCNiCu}$ increases by $30 \%$, while that of steel $20 \mathrm{Cr} 2 \mathrm{Ni} 4 \mathrm{~A}$ and $18 \mathrm{CrMnTi}$ remains almost unchanged.

Studies have been conducted on structural alloyed steel $15 \mathrm{CrC} 2 \mathrm{Ni2} \mathrm{Mg}$ to identify the capabilities of the combined hardening technology, consisting of operations of preliminary WDH and subsequent cementation.

\section{Results and discussion}

As a result of experimental studies of the combined hardening of steel $15 \mathrm{CrC} 2 \mathrm{Ni} 2 \mathrm{Mg}$, a significant effect of preliminary WDH on the subsequent cementation is established. It is found that when hardening by the cementation only, the maximum hardness is $62 \mathrm{HRC}$, whereas the use of preliminary WDH with combined hardening increases the maximum hardness to $65 \mathrm{HRC}$, and this hardness occurs in the surface layer up to $1.5 \mathrm{~mm}$ in depth (Fig. 1).

It is found that the impact resistance (KCU) of the samples obtained only by cementing and combined hardening did not change and was accordingly $16.24 \mathrm{~J} / \mathrm{cm}^{2}$ and $16.41 \mathrm{~J} / \mathrm{cm}^{2}$, whereas for structural steel $10 \mathrm{CrCNiCu}$, the impact resistance (KCU) decreased after the cementation by more than two times, it was $63.44 \mathrm{~J} / \mathrm{cm}^{2}$, and after combined hardening it was $28.57 \mathrm{~J} / \mathrm{cm}^{2}$.

The article studied the microstructure of the samples hardened as a result of chemical heat treatment (CHT) that is the cementation followed by quenching and tempering, as well as the samples receiving combined hardening of WDH and CHT. (Fig. 2).

Studies show that as a result of combined hardening, the cemented layer has not only a greater depth, but also a more uniform evenly crushed structure, martensite needles are 6 or more times as small, moreover, they are much more densely packed. While under cementing without WDH in the middle part of the cemented layer a loosening zone is observed with coarse multidirectional martensite needles, interspersed with inclusions of plastic phase.

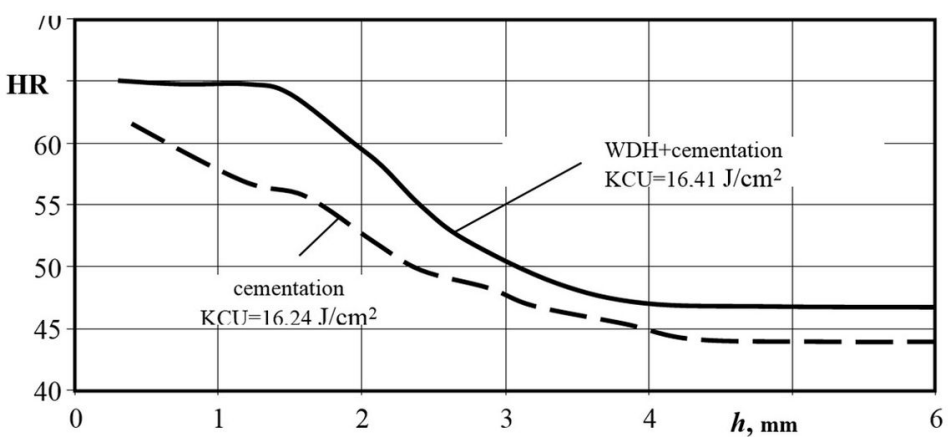

Fig. 1. The pattern of changing hardness over the surface layer depth of steel $15 \mathrm{CrC} 2 \mathrm{Ni} 2 \mathrm{Mg}$, hardened by the cementation without using WDH and using WDH 


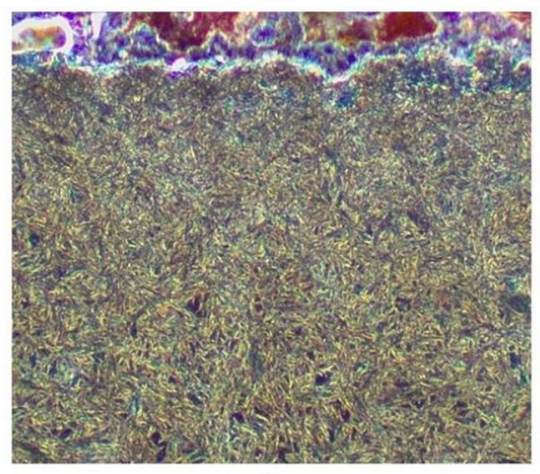

a)

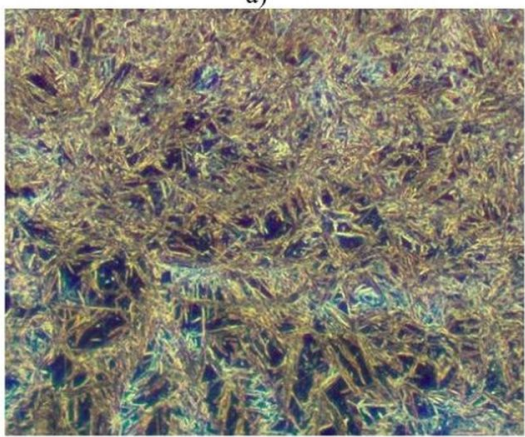

c)

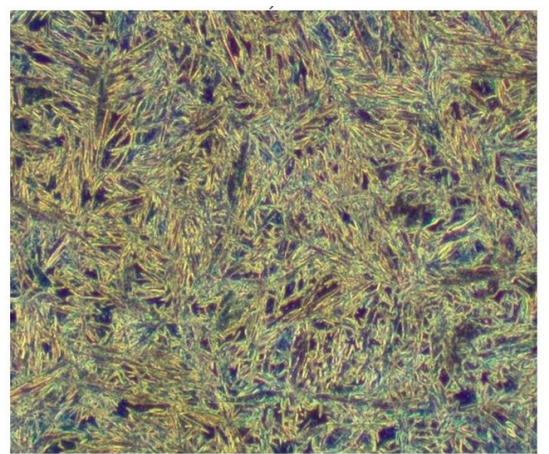

e)

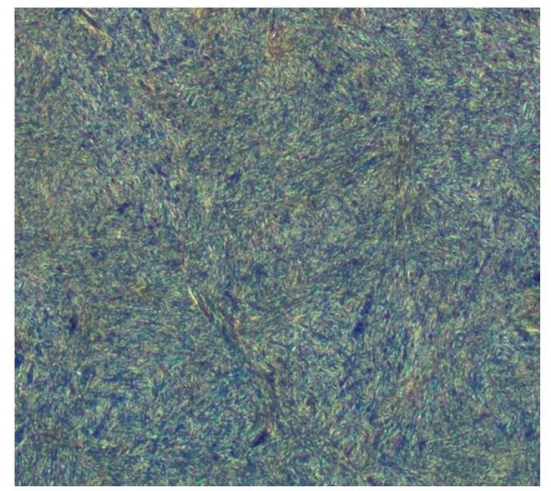

g)

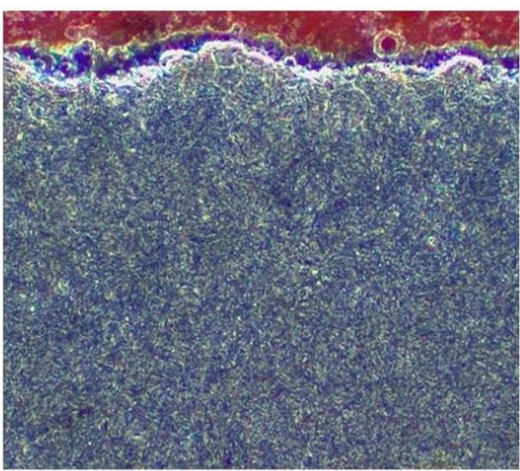

b)

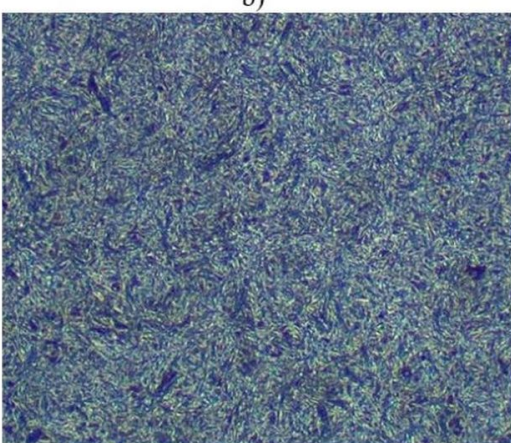

d)

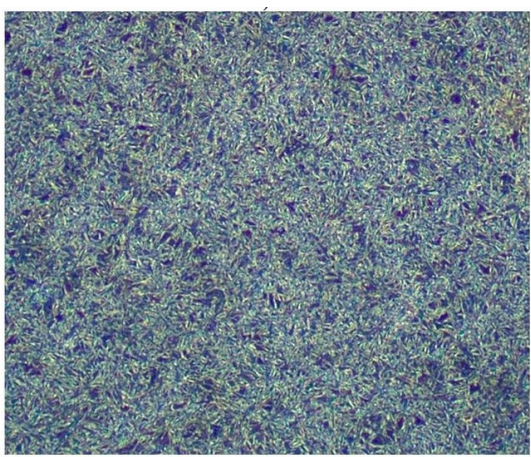

f)

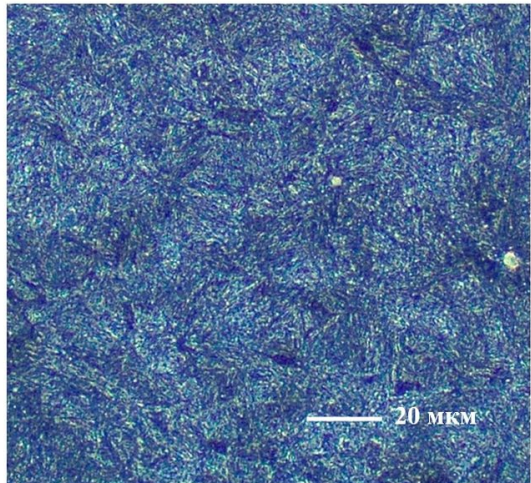

h) 
Fig. 2. The microstructure (magnification $2550^{*}$ ) of steel $15 \mathrm{CrC} 2 \mathrm{Ni} 2 \mathrm{Mg}$, hardened by the cementation: a, c, e, g- without WDH; b, d, f, h-using WDH; a, b - the outer surface of the samples; c, d - the martensitic zone, the depth 200-500 microns; e, $\mathrm{f}$ - the lower boundary of the cemented layer, the depth 1400-1800 microns; $\mathrm{g}, \mathrm{h}$ - the sample core

The sample, hardened only by the cementation, has several zones with a different structure in the surface layer. The outer cemented layer, decarburized as a result of quenching and tempering at a depth of up to $60 \mu \mathrm{m}$ has a homogeneous fine-dispersed structure (Fig. 2, a). In a deeper sublayer, deeper than 60 microns, martensite needles are observed in the structure, increasing in size to 30 microns as they deepen. At a depth of about $220 \mu \mathrm{m}$, martensite needles of different sizes are located with various densities (Fig. 2 , c), which can be explained by different cooling rates during quenching, which is not constant in depth. In the center of the needle-like zone (at a depth of approximately 700 $\mu \mathrm{m}$ ), the structure of coarse-needle martensite (the needle length is up to $80 \mu \mathrm{m}$ ) with regions of troostite-sorbitol tempering can be observed. As the depth increases, from 1360 microns, the dispersion and density of the twin boundaries decrease in gradient, while remaining in the martensitic phase. At a depth of 1360 microns, martensite needles are located with different packing densities. Next, the needles gradually decrease in size to 10 $\mu \mathrm{m}$ with increasing the packing density (Fig. 2, e). The martensitic structure of the cemented layer transforms into a uniform fine-grained structure of the sample core (Fig. 2, g) approximately at a depth of $2600 \mu \mathrm{m}$.

The microstructure of the sample subsurface layer, hardened by WDH and CHT, is finegrained and uniform (Fig. 2, b). At a depth of 350 ... 570 microns, the structure of fineneedle martensite is formed with the needles up to 5-7 microns in size (Fig. 2, d). Such a structure is maintained to a depth of $1800 \mu \mathrm{m}$, then a microstructure is formed (Fig. 2, f), close to the uniform fine-grained structure of the sample core - temporal troposite-sorbitol, against the background of which the acicularity of undecomposed martensite remains (Fig. $2, \mathrm{~h}$ ). Due to plastic deformation and forming a high density of defects in the crystal structure resulting from the WDH, the core structure of the sample is fine-grained. The subsurface layer structure of the opposite outer side of the sample is fine, uniform. At a depth of $280 \ldots 1200 \mu \mathrm{m}$, the finely dispersed structure is replaced by a small-needle martensitic, then (after $1200 \ldots 1600 \mu \mathrm{m}$ ) is replaced by martensitic structure with the stripes of troostite-sorbitol tempering.

\section{Conclusions}

It has been established that for steel $15 \mathrm{CrC} 2 \mathrm{Ni} 2 \mathrm{Mg}$, using $\mathrm{WDH}$ before the cementation promotes grinding the structure throughout the depth of hardening, which allows forming a smoother layer-by-layer gradient transition of properties. The uniform high packing density and smaller sizes of martensite needles in the subsurface layer and on the border of the cemented layer, in the sample core, as well as the absence of large-needle martensite, allows, unlike hardening only by the cementation, increasing the effective hardness, forming a uniform hardness of $65 \mathrm{HRC}$ to a depth of $1.5 \mathrm{~mm}$, with its gradual decrease to the sample core, while maintaining a high level of impact strength. The combined hardening of $\mathrm{WDH}$ and $\mathrm{CHT}$ has a great potential to increase the wear resistance of parts during the operation under conditions of sliding friction and the action of shock loads.

\section{References}

1. V.A. Lebedev, A.V. Kirichek, V.D. Sokolov, Proc. Engin., 150, 775 (2016) 
2. L.S. Malinov, V.A. Kharlashkin, Metal. Min. Ind., 3:2, 58 (2011)

3. E.A. Marinin, S.P. Grachev, A.L. Flaxman. Mater.s Sc. For., 870, 377 (2016)

4. A.V. Kirichek, D.L. Solov'ev and S.A. Silant'ev, Forg. Stamp. Prod. (Mat. Work. Press.), 10, 35 (2002)

5. A.V. Kirichek, D.L. Solov'ev, Forg. Stamp.Prod. (Mat. Work.Press.), 7, 28 (2001)

6. A.V.Kirichek, D.L. Soloviev and A.Yu. Altuhov J. Nan.Electr.Phys., 6:3, 03069 (2014)

7. A.V. Kirichek and D. L. Soloviev. IOP Conf. Series: Mat. Sc.Engin., 124, 012159 (2016)

8. A.V. Kirichek, D.L.Soloviyov, S.A. Silantiev. Mater. Sc. For., 870, 364 (2016)

9. A.V. Kirichek, D.L. Solov'ev, Silant'ev, Forg. Stamp. Prod. Met. Form. 2, 13 (2004)

10. A.V. Kirichek and D.L. Solov'ev, Rus. Engin. Res., 28:3, 277 (2008)

11. A.V. Kirichek and D.L. Soloviev, J. Nan. Electr. Phys., 5:4, 04010 (2013)

12. A.V. Kirichek, D.L. Soloviev and A.Yu. Altuhov, J. Nan. Electr. Phys., 6:3, 03070 (2014)

13. A.V. Kirichek and D.L. Soloviev, J. Nan. Electr. Phys., 5:4, 04009 (2013)

14. A.V. Kirichek, A.P. Kuzmenko, D.L. Soloviev, S.V. Barinov, A.Yu. Altukhov, S.A. Silantiev, A.N. Grechukhin, Myo Min Than, M.B. Dobromyslov, J. Nan. Electr. Phys., 7:4, $04023(2015)$

15. A.V. Kirichek, D.L. Soloviev and S.A. Silant'ev. IOP Conf. Series: Mat. Sc.Engin., 124, 012157 (2016)

16. A.V. Kirichek, A.Y. Altukhov, D.L. Solovyov, Silantiev S.A., J. Nan. Electr. Phys. 7:4, 04082 (2015)

17. A.I. Boldyrev, A.A. Boldyrev, O.N. Fedonin. MATEC W.Conf. 224, 01097 (2018) 